\title{
Antithiamine Action of Aminothiamine
}

\author{
Akio Iwashima, Taro Nakata, Toru Masuda \\ AND Yoshitsugu Nose ${ }^{2}$
}

Biochemical Institute, Kyoto Prefectural University

of Medicine, Kawaramachi, Kyoto (Post No.602)

(Received December 11, 1967)

\begin{abstract}
1. Aminothiamine inhibits the growth of thiamine requiring $L$. fermenti by competing with thiamine, the inhibition index being 450 to 470 .
\end{abstract}

2. Aminothiamine inhibits competitively uptake of thiamine by resting cells of baker's yeast and $L$. fermenti.

3. Aminothiamine inhibits baker's yeast thiamine kinase.

4. As one of the sites of antithiamine action of aminothiamine on microorganism the competition between thiamine antagonist and thiamine in the process of permeation into cell membrane was discussed.

It is well known that aminothiazole $\left(\mathrm{NH}_{2}-\mathrm{Th}\right)$ which has an amino group on $\mathrm{C}_{2}$ position of $\mathrm{Th}$ inhibits the growth of Escherichia coli (1) and Saccharomyces cerevisiae (2). Nakayama (1) suggested that the growth inhibition of Escherichia coli by $\mathrm{NH}_{2}$ - Th is caused by a competitive inhibition in the condensation reaction between OMPm and Th in thiamine biosynthesis de novo by this organism.

On the other hand, the authors (3-5) investigated the inhibition mechanism of thiamine biosynthesis by $\mathrm{NH}_{2}$-Th using thiamine synthesizing enzyme system extracted from baker's yeast and demonstrated that two successive competitive inhibitions, one in the step of Th-kinase (EC 2.7.1.50) reaction by $\mathrm{NH}_{2}$-Th, the other in the step of TMP pyrophosphorylase (EC 2.5.1.3) reaction by $\mathrm{NH}_{2}-\mathrm{Th}-\mathrm{P}$, formed from $\mathrm{NH}_{2}$-Th by Th-kinase, are responsible to the inhibitory reaction and there is an enzymatic synthesis of aminothiamine as a result of the overall reaction (Fig. 1).

Aminothiamine has been chemically synthesized by Matsukawa et al. (6) and Kimura et al. (7) reported on biological action of this compound which inhibits the growth of Staphylococcus aureus by competing with thiamine. Many papers concerning thiamine antagonists have been already reported, especially the inhibition mechanisms of neopyrithiamine (8) and oxythiamine (9) were investigated at

\footnotetext{
${ }^{1}$ Following abbreviations were used: OMPm, 2-methyl-4-amino-5-hydroxymethylpyrimidine; Th, 4-methyl-5- $\beta$-hydroxyethylthiazole; OMPm-P, OMPm-monophoshate; OMPm-PP, OMPmdiphosphate; Th-P, Th-monophosphate; $\mathrm{NH}_{2}$-Th, 2 -amino-4-methyl-5- $\beta$-hydroxyethylthiazole; $\mathrm{NH}_{2}$-Th-P, $\mathrm{NH}_{2}$ - Th-monophosphate; TMP, thiamine monophosphate; $\mathrm{NH}_{2}-\mathrm{B}_{1}-\mathrm{P}$, aminothiamine monophosphate; $\mathrm{DOB}_{1}$, deoxythiamine; $\mathrm{DOMB}_{1}$, deoxymethylthiamine; $\mathrm{DOEB}_{1}$, deoxyethylthiamine.

2 岩島昭夫, 中田太郎, 增田烹, 能勢善嗣.
} 


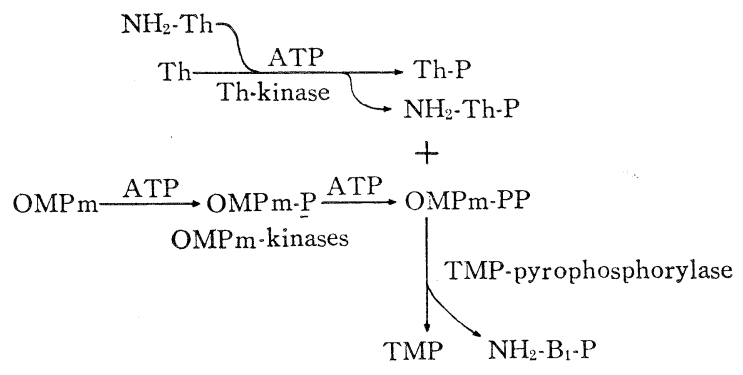

FIG. 1 Inhibition Mechanism of Thiamine Biosynthesis by Aminothiazole

enzymatic levels. Recently Kawasaki et al. (10-13) investigated the systematic studies about thiamine antagonists and they reported mainly on structurely related compounds to thiamine, which had different groups from thiamine on $\mathrm{C}_{5}$ position of Th moiety including imidazole thiamine. The authors noticed a similarity of the structure between thiamine and aminothiamine. There is only a difference in a group on $\mathrm{C}_{2}$ position of Th moiety which is important to show physiological actions as a coenzyme. Therefore, the authors investigated the effects of this compound on the growth of thiamine requiring Lactobacillus fermenti, the effect on uptake of thiamine into the cells of yeast and L. fermenti and the effect on yeast thiamine kinase (EC 2.7.6.2). The antithiamine actions of aminothiamine were demonstrated by using these biological systems and it was suggested that the competition between thiamine and thiamine antagonists in the process of their permeation into living cells should be considered as one of plausible sites of the action to clarify the mechanism of various thiamine antagonists, although the mechanism of permeation has not yet been clearly elucidated.

\section{EXPERIMENTAL}

\section{Growth Inhibition Test of Lactobacillus fermenti}

Lactobacillus fermenti-36 (ATCC 9338) which strictly requires thiamine for growth was used as a test organism. Thiamine assay medium (Difco Co.) was applied for stock, preculture and basal media. Thiamine was added to both stock and preculture media at final concentration of $1 \times 10^{-7} M$. Cells were collected after overnight preculture, washed twice with sterile saline solution, and diluted up to 50 volumes with sterile saline. One drop each of the cell suspensions was innoculated in $5 \mathrm{ml}$ of basal medium. The concentration of thiamine added to basal medium was $1 \times 10^{-9}$ or $1 \times 10^{-8} M$ in final concentration, whereas aminothiamine was added in the range of the concentration between $1 \times 10^{-7}$ and $1 \times 10^{-5} \mathrm{M}$.

The growth was measured using Klett-Summerson photoelectric colorimeter (Filter 560) after 20 hour incubation at $37^{\circ}$ and it was represented by the reading values.

2. Experiment on Uptake of Thiamine by Resting Cells of Baker's Yeast and L. fermenti

In the experiment with baker's yeast the following condition, the modified 
reaction system reported previously by Suzuoki (14), was employed. The reaction mixture contained $100 \mu$ moles of Tris-maleate buffer ( $\mathrm{pH} 7.0$ ), 10 or 100 m $\mu$ moles of thiamine, $1 \mathrm{ml}$ of $10 \%$ glucose and $1 \mathrm{ml}$ of $10 \%$ cell suspension of baker's yeast (Oriental Co.) in a total volume of $5 \mathrm{ml}$. The mixture was incubated at $38^{\circ}$ for 10 minutes without shaking. Immediately after the incubation the mixture was centrifuged and sedimented cells were washed with $10 \mathrm{ml}$ of $0.1 \mathrm{M}$ acetate buffer ( $\mathrm{pH} 4.5)$ twice and then suspended in $10 \mathrm{ml}$ of the same buffer, extracted thiamine by heating at $85^{\circ}$ for 15 minutes. Both total thiamine in cells and free thiamine remained in the supernatant were estimated by thiochrome method using permutit (15).

L. fermenti 36 (ATCC 9338) was grown in $600 \mathrm{ml}$ of thiamine assay medium containing $2 \times 10^{-8} \mathrm{M}$ thiamine at $37^{\circ}$ for 20 hours. The cells grown were harvested, followed by washing twice with sterile saline solution and suspended in the saline in adequate concentration. $1 \mathrm{ml}$ of the cell suspension was used in the reaction. The reaction condition was similar to that used in the experiment with baker's yeast.

\section{Experiment on Yeast Thiamine Kinase}

Thiamine kinase was prepared from baker's yeast according to the method previously described by Tokuda (16) and the ammonium sulfate fraction (0.5 to 0.6 saturation) was used in the experiment. Assay of thiamine kinase was carried out following the procedure previously reported (16) and preparation of apocarboxylase and manometric determination of cocarboxylase was carried out according to Aoshima's method (17).

\section{RESULTS}

\section{Effect of Aminothiamine on the Growth of L. fermenti}

As shown in Fig. 2, the growth of L. fermenti began to be inhibited by addition of $1 \times 10^{-6} M$ aminothiamine in the presence of $1 \times 10^{-8} M$ thiamine and it

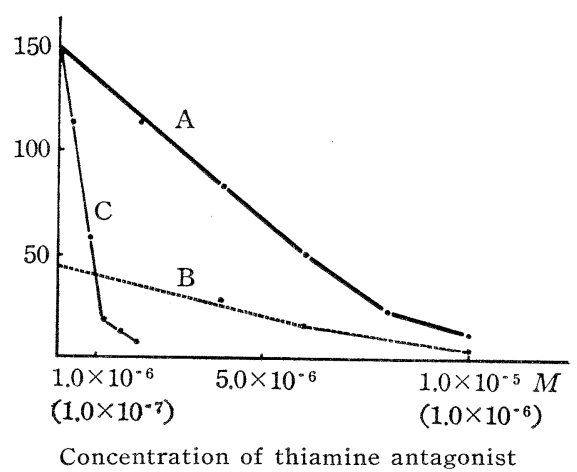

FIG. 2 Effect of Aminothiamine on the Growth of Lactobacillus fermenti 36 A, thiamine, $1 \times 10^{-8} \mathrm{M}$, was added; $\mathrm{B}$, thiamine, $1 \times 10^{-9} \mathrm{M}$, was added. The parenthesized figures show the concentration of aminothiamine. $\mathrm{C}$, thiamine, $1 \times 10^{-8} \mathrm{M}$, was added. The parenthesized figures show the concentration of neopyrithiamine. 
was completely inhibited by $1 \times 10^{-5} M$ aminothiamine. The growth in the presence of $1 \times 10^{-9} \mathrm{M}$ thiamine was also completely inhibited by the addition of $1 \times 10^{-6} \mathrm{M}$ aminothiamine. The concentration of aminothiamine needed for $50 \%$ inhibition of the growth was $4.5 \times 10^{-6}$ and $4.7 \times 10^{-7} M$ respectively. The inhibition index was 450 to 470 , showing that the type of growth inhibition by aminothiamine was competitive. However, the inhibition by aminothiamine was considera bly low as compared with that by pyrithiamine (inhibition index was 7).

2. Effect of Aminothiamine on Uptake of Thiamine by Baker's Yeast Cell.

On the mechanism of thiamine antagonists, competition of thiamine and the antagonist on thiamine kinase reaction and binding competition of cocarboxylase and pyrophosphate ester of the antagonist formed on apocarboxylase have been generally noticed. However, a possibility of competition of thiamine and the antagonist on the cell membrane in the permeation process, first of all, should be considered to study the mechanism of growth inhibition of microorganism by thiamine antagonists. It has been reported that the uptake of thiamine across the membrane of microorganisms is involved in an active transport process requiring metabolic energy. Suzuoki, for instance, demonstrated that uptake of thiamine by baker's yeast cell was remarkably inhibited by addition of glycolysis inhibitors such as iodoacetic acid and sodium fluoride, dinitrophenol and sodium azide. The authors investigated the effect of aminothiamine on uptake of thiamine by resting cells of baker's yeast under the experimental condition described above. As the result shown in Table 1 the uptake of thiamine, when $10 \mathrm{~m} \mu$ moles of thiamine was added to the reaction mixture, was inhibited 42.2 per cent in the presence of the equivalent amount of aminothiamine and further the inhibition was increased by increasing the amount of aminothiamine added. When thiamine added was increased up to $100 \mathrm{~m} \mu$ moles, the uptake was inhibited 65.1 per cent in the presence of the equivalent amount of aminothiamine. These results show that uptake of thiamine by cells is inhibited competitively by aminothiamine. The effects of oxythiamine, one of well known thiamine antagonists, $\mathrm{OMPm}$ and $\mathrm{NH}_{2}$ - $\mathrm{Th}$, corresponding to pyrimidine and Th moieties of thiamine, were also investigated. As shown in Table 2, only OMPm showed a significant inhibitory action when it was added up to 50 fold amount of thiamine, whereas inhibitory action of the others were below one fiftieth of that by aminothiamine.

TABLE 1

Effect of Aminothiamine on Uptake of Thiamine by Resting Cells of Baker's Yeast

\begin{tabular}{cccc}
\hline \hline Addition & $\begin{array}{c}\text { Thiamine } \\
\text { in cells }\end{array}$ & $\begin{array}{c}\text { Thiamine } \\
\text { in medium }\end{array}$ & Inhibition \\
\hline mpmoles & mumoles & mumoles & per cent \\
Thiamine (10) & 9.0 & 0.5 & \\
+ Aminothiamine (10) & 5.2 & 4.8 & 42.2 \\
+ Aminothiamine (20) & 3.3 & 6.4 & 63.3 \\
+ Aminothiamine (50) & 1.4 & 7.4 & 84.4 \\
Thiamine (100) & 30.1 & 59.9 & 65.1 \\
+ Aminothiamine (100) & 10.5 & 91.2 & 84.7 \\
+ Aminothiamine (200) & 4.6 & 99.4 & 94.0 \\
+ Aminothiamine (500) & 1.8 & & \\
\hline
\end{tabular}


TABLE 2

Effect of Oxythiamine, OMPm and $\mathrm{NH}_{2}$-Th on Uptake of Thiamine by Resting Cells of Baker's Yeast

\begin{tabular}{ccc}
\hline \hline Addition & $\begin{array}{c}\text { Thiamine } \\
\text { in cells }\end{array}$ & Inhibition \\
\hline mumoles & mumoles & per cent \\
Thiamine (10) & 10.0 & \\
+Oxythiamine (50) & 9.7 & 3.0 \\
+Oxythiamine (500) & 9.1 & 9.0 \\
+OMPm (50) & 6.4 & 36.0 \\
+OMPm (500) & 1.7 & 83.0 \\
+ $\mathrm{NH}_{2}$-Th (50) & 8.8 & 12.0 \\
+ $\mathrm{NH}_{2}$-Th (500) & 7.6 & 24.0 \\
\hline
\end{tabular}

3. Effect of Aminothiamine on Uptake of Thiamine by L. fermenti.

Since aminothiamine inhibited the growth of $L$. fermenti by competing with thiamine as described above, the effect of aminothiamine on uptake of thiamine by resting cells of $L$. fermenti was investigated using the same method employed in the experiment with baker's yeast. As shown in Table 3, the uptake of thiamine by cells was inhibited 59.7 per cent by addition of aminothiamine with 100 fold amount of thiamine, and completely inhibited by that with 1000 fold amount of thiamine. Although the inhibitory action of aminothiamine was considerably low as compared with the case of baker's yeast, it was demonstrated that the uptake of thiamine by resting cells of $L$. fermenti was also inhibited by aminothiamine. These results suggest that thiamine antagonists can compete with thiamine on the cell membrane of microorganisms which seem to take thiamine up into cells by an active transport process, rather than by passive diffusion.

TABLE 3

Effect of Aminothiamine on Uptake of Thiamine by Resting Cells of Lactobacillus Fermenti

\begin{tabular}{ccc}
\hline Addition & $\begin{array}{c}\text { Thiamine } \\
\text { in cells }\end{array}$ & Inhibition \\
\hline mumoles & mumoles & per cent \\
Thiamine $(10)$ & 7.7 & 9.1 \\
+ Aminothiamine $(100)$ & 7.0 & 59.7 \\
+ Aminothiamine $(1,000)$ & 3.1 & 92.2 \\
+ Aminothiamine $(10,000)$ & 0.6 & \\
\hline
\end{tabular}

Dry weight of the cells of L. fermenti used was $32.0 \mathrm{mg}$ and incubation period was 30 minutes.

\section{Effect of Aminothiamine on Yeast Thiamine Kinase Reaction.}

Even if the primary site of antithiamine action of aminothiamine may be its competition with thiamine on the cell membrane in the process of permeation, the effect of aminothiamine on thiamine kinase, which has been believed as one of the most probable site of the action of thiamine antagonists, should be reasonably considered. Table 4 shows the results obtained using thiamine kinase partially purified from baker's yeast. The inhibition of the enzyme by aminothiamine was fairly low and the reaction was inhibited 30 per cent by the addition of aminothiamine with 250 to 500 fold amount of the substrate, and completely inhibited 
TABLE 4

Effect of Aminothiamine on Yeast Thiamine Kinase Reaction

\begin{tabular}{ccc}
\hline \hline Addition & Evolution of $\mathrm{CO}_{2}$ & Inhibition \\
\hline mumoles & $\mu l$ & per cent \\
Thiamine (30) & 187.0 & \\
+ Aminothiamine (3) & 186.0 & 0.5 \\
+ Aminothiamine (7.5) & 116.2 & 37.8 \\
+ Aminothiamine (15) & 69.1 & 63.0 \\
+ Aminothiamine (30) & 0 & 100.0 \\
+ Neopyrithiamine (300) & 12.5 & 93.3 \\
\hline
\end{tabular}

by the addition of the antagonist with 1,000 fold amount of thiamine, whereas pyrithiamine inhibited completely the reaction by the addition of 10 fold amount of thiamine.

\section{Discussion}

Aminothiazole, which inhibits the growth of $E$. coli by competing with Th in thiamine biosynthesis de novo, was found to inhibit as a competitive substrate in the steps of conversion of $\mathrm{Th}$ to thiamine using thiamine synthesizing enzyme system extracted from baker's yeast. It was also found that aminothiamine incorporating $\mathrm{NH}_{2}$-Th into $\mathrm{Th}$ moiety of thiamine was formed in this reaction. Breslow (18) and others proposed hydroxyethylthiamine pyrophosphate, which has an $\alpha$-hydroxyethyl group on $\mathrm{C}_{2}$ position of $\mathrm{Th}$ moiety of thiamine, as an active intermediate in the coenzyme action of thiamine and it has been demonstrated and widely supported now. Aminothiamine has a similar structure, the hydrogen atom being replaced by $\mathrm{NH}_{2}$ group on $\mathrm{C}_{2}$ position of Th moiety of thiamine. Thus, because of the structural similarity to thiamine the antagonisity of aminothiamine to thiamine seems to be an interesting problem to be investigated.

Kawasaki (10), Hiraoka et al. $(11,12)$ demonstrated some antagonisities of various thiamine derivatives with modified radical of $\mathrm{C}_{5}$ side chain of Th moiety, which is phosphorylated to convert coenzyme form of thiamine, using L. fermenti and Kl. apiculata. From the results the authors investigated the effect of aminothiamine on the growth of L. fermenti it was demonstrated that aminothiamine acted as a thiamine antagonist, as expected, by competing with thiamine on the growth of the bacteria. The inhibition index was 450 to 470 and it was more effective than oxythiamine and nearly as effective as $\mathrm{DOB}_{1}, \mathrm{DOMB}_{1}, \mathrm{DOEB}_{1}$ and imidazole- $\mathrm{B}_{1}$ reported by Kawasaki et al., whereas it was far less effective than pyrithiamine.

Although the mechanism of permeation of thiamine into the cell has not yet been clarified, several workers have reported that uptake of thiamine by living cells may be carried out by some enzyme systems localized around cell membrane using baker's yeast (14), L. fermenti (19) and rat brain cortex (20). As one of the sites for antithiamine action of thiamine antogonists, at least as observed as the growth inhibition of microorganism, the competition between the antagonists and thiamine in the process of their permeation into the cell should be reasonably considered. Aminothiamine seems to be useful to investigate the influence on permeability of thiamine, because of its inability to be converted to thiochrome 
by alkaline ferricyanide or cyanogen bromide. As the results, the authors investigated the effect of aminothiamine on uptake of thiamine by resting cells of baker's yeast. It was found that aminothiamine inhibited competively uptake of thiamine, whereas oxythiamine hardly competed with thiamine as Suzuoki (14) reported previously, and OMPm showed significant competition on uptake of thiamine. On the other hand, Kawasaki et al. also demonstrated specific inhibitory action of pyrimidine compounds, having a methylene group on $\mathrm{C}_{5}$ position of pyrimidine moiety like thiamine, on the growth of L. fermenti and Kl. apiculata and they suggested a possibility of the inhibitory action of these compounds on uptake of thiamine by cells. It was found that aminothiamine, which inhibited the growth of L. fermenti, showed an inhibitory effect on uptake of thiamine by cells, although the inhibition was less than the case with baker's yeast. There are remarkable differences in inhibitory effect of thiamine antagonists on thiamine uptake in the species of microorganisms used. Such a difference may depend on the difference in the requirement of thiamine, content of thiamine and capacity for uptake of thiamine by microorganisms.

The effect of aminothiamine on thiamine kinase reaction which is supposed to be one of the most important sites of action of thiamine antagonists, was investigated using the enzyme partially purified from baker's yeast. Aminothiamine showed more significantly inhibitory effect than that of oxythiamine (23), but it was far less than that of pyrithiamine previously reported. In a preliminary experiment the authors (24) have also observed that a chemically synthesized aminothiamine pyrophosphate competes with cocarboxylase on yeast carboxylase reaction.

As expected, it is supposed to be difficult to decide the primary site of antithiamine action of aminothiamine from these results obtained above, since aminothiamine showed competitive inhibitions on various steps in several thiamine involving biological reactions. However, it was at least suggested that the competition between thiamine antagonists and thiamine in the process of their permeation into the cell should be considered as one of the most plausible sites of thiamine antagonists except competition on thiamine kinase reaction and on the binding reaction to apocarboxylase.

\section{ACKNOWLEDGEMENT}

The authors wish to thank Dr. S. Yurugi, Research Laboratories, Takeda Pharmaceutical Industries Ltd., Osaka, for generous gift of the preparation of aminothiamine, and also wish to thank Dr. Y. Tokuda for his technical help in the experiment.

\section{REFERENCES}

1. Nakayama, H., Vitamins, 11, 20 (1956).

2. Nose, Y., and Iwashima, A., Lipmann's Dedicatory Volume, Academic Press (1966).

3. Iwashima, A., Seikagaku, 36, 147 (1964).

4. Iwashima, A., Seikagaku, 36, 194 (1964).

5. Iwashima, A., Tokuda, Y., and Nose, Y., Seikagaku, 36, 642 (1964).

6. Matsukawa, T., Iwatsu, T. and Yurugi, S., J. Pharm. Soc. Japan, 71, 1239 (1951).

7. Kimura, R., and Hayashi, R., Vitamins, 2, 263 (1949).

8. Wolley, D. W., J. Biol. Chem., 191, 43 (1951). 
9. Eusebi, A. J., and Cerecedo, L. R., Fed. Proc., 9, 169 (1950).

10. Kawasaki, C., and Hiraoka, E., Vitamins, 22, 197 (1961).

11. Hiraoka, E., Tomita, I., and Simada, H., Vitamins, 22, 200 (1961).

12. Hiraoka, E., and Simada, H., Vitamins, 23, 213 (1962).

13. Kawasaki, C., Yamada, C., Itoh, Y., and Kurata, G., Vitamins, 32, 323 (1965).

14. Suzuoki, J., J. Biochem., 42, 27 (1955).

15. Fujita, A., Methods of Vitamin Assay (Japanese), p. 221, Nankodo, Kyoto (1955).

16. Tokuda, Y., Vitamins, 29, 40 (1964).

17. Aoshima, Y., Seikagaku, 29, 861 (1958).

18. Breslow, R., J. Am. Chem. Soc., 80, 3719 (1958).

19. Naujahr, H. Y., Sixth Intern. Congr. Biochem. Abstract, p. 661 (1964).

20. Sarma, S. K., and Quastel, J.H., Biochem. J., 94, 790 (1965).

21. Kawasaki, C., Okada, K., Fujita, Y., and Shinke, H., Vitamins, 30, 350 (1964).

22. Kawasaki, C., Okada, K., and Fujita, Y., Vitamins, 30, 354 (1964).

23. Kajiro, Y., J. Biochem., 46, 1523 (1959).

24. Iwashima, A., and Tokuda, Y., unpublished. 